\title{
Política y discurso en el tratamiento al tema migratorio de la $4 \mathrm{~T}^{*}$ / Policy and discourse
} on the subject of migration in the $4 T$

\section{Dunia Eduvijes Jara Solenzar** Jorge Morales Brito***}

\section{RESUMEN}

El artículo presenta los resultados del análisis sobre posturas políticas asumidas respecto al tema migratorio en el discurso del presidente de México, Andrés Manuel López Obrador. Se devela la perspectiva discursiva del proyecto de nación (2018-2024) como marco de referencia de la política migratoria. El énfasis del estudio constata las fluctuaciones en el tratamiento al fenómeno migratorio durante el 2019, por las tensiones y conflicto de intereses entre México, Estados Unidos y Centroamérica. Los principales hallazgos muestran la evolución de temas en el discurso político que, por su estabilidad y caída, apuntan hacia la efectividad o no de un nuevo enfoque de gestión migratoria. Se concluye con la posibilidad de nuevas vias de indagación empírica en la evaluación de políticas públicas.

PALABRAS CLAVE: Política, discurso, AMLO, migrante objeto, migrante sujeto.

\begin{abstract}
The present article presents the results of analysis undertaken on the political postures taken on the subject of migration in the discourse of the President of Mexico, Andrés Manuel López Obrador, revealing the discursive perspective of the national project (2018-2024) as a framework for migration policy. The emphasis of the present study demonstrates the fluctuations in the treatment of the migratory phenomenon in 2019, in the context of tensions and conflicting interests among Mexico, the United States, and Central America. The main findings show the evolution of topics in the political discourse that, in either stability or collapse, point to the effectiveness, or lack thereof, of a new focus for migration management. The present article concludes by highlighting new potential lines of empirical enquiry in the evaluation of public policy.
\end{abstract}

KEY WORDS: Policy, discourse, AMLO, migrant as object, migrant as subject.

\footnotetext{
* Artículo de investigación. Recibido el 19 de enero de 2020 y aceptado para su publicación el 2 de septiembre de 2020.

** Becaria de AMEXCID y la Secretaria de Relaciones Exteriores del Gobierno de México en el Instituto de Ciencias Sociales y Humanidades "Alfonso Vélez Pliego" de la Benemérita Universidad Autónoma de Puebla, México. 1 duniajs2018@gmail.com / orcid.org/0000-0002-5482-465X

*** Profesor en la Universidad Central Marta Abreu de las Villas, Cuba. / jmbrito80@nauta.cu / orcid.org 10000-0003-3124-8458
} 


\section{SUMARIO}

1. Introducción

2. La migración de tránsito por México hacia Estados Unidos

3. Noción del migrante sujeto y del migrante objeto en el discurso político

4. El tema migratorio en el discurso y acción política del gobierno de Andrés Manuel López Obrador

5. Conclusiones

\section{Introducción}

Las condiciones sociales que emergieron del acuerdo migratorio Estados Unidos-México definen el curso de las acciones alrededor del tema en la actual Administración mexicana. Las tensiones y conflictos de intereses políticos y económicos fijaron una nueva visión de país en el tratamiento discursivo sobre el tema migratorio.Tales aspectos centran el análisis del discurso político manifiesto en la producción e interpretación de la política migratoria en México, así como en sus efectos para la población migrante.

La gestión del presidente Andrés Manuel López Obrador suscribe una estrategia migratoria en búsqueda de formas más efectivas que alcancen la reducción del flujo hacia México y Estados Unidos. Si ubicamos en contexto la compleja realidad del sistema migratorio Centroamérica-México-Estados Unidos, "la migración se sigue manifestando como la tradicional válvula de escape ante la presión que ejerce la crisis humanitaria y de violencia social y económica en la región". ${ }^{1}$ Aquí, la política de los gobiernos y sus implicaciones en el tejido social muestran los desafíos de la migración como un problema global.

Los cambios en la política migratoria mexicana refieren a momentos históricos marcados por las relaciones entre Estados Unidos y México. Ello indica etapas de limitado flujo migratorio, dado el reforzamiento de medidas antiinmigratorias, así como etapas de movilidad humana sin precedentes. La migración ha puesto en crisis a los gobiernos y su política exterior. El caso de México ilustra cómo se genera una crisis de significados de la política migratoria y del enfoque de relaciones con Centroamérica y Estados Unidos.

Por un lado, la tendencia histórica de las relaciones Estados Unidos-MéxicoCentroamérica reafırma el carácter de su política en los procesos migratorios

\footnotetext{
DURAnd, JoRge, "Política migratoria: entre el discurso, la práctica y la coyuntura" Foro Internacional, vol. 59, núm. 34, 2019, p. 1044. Disponible en: http://dx.doi.org/10.24201/fi.v59i3-4.2650
} 
y, por otro, el discurso proactivo y de cooperación de la actual administración supone la transformación de la política migratoria. En este sentido, se recurre a los fundamentos teóricos y metodológicos de la política del discurso, ${ }^{2}$ para distinguir lo proactivo como discurso presente en el programa de gobierno de AML0. Para el caso que nos ocupa, resulta relevante la visión de país sobre las causas, vías y estrategias para atender el fenómeno migratorio en el discurso político.

En este artículo, se analiza el tratamiento al tema migratorio como muestra de la evolución en la prática política de López Obrador, pues, en su discurso, perfilan momentos de auge y disminución en el tratamiento al tema. Por ello, nos planteamos realizar el estudio a partir de las siguientes interrogantes:

- ¿Qué condicionantes determinan el discurso y acción política de la actual Administración mexicana?

- ¿Cuáles son los tópicos de interés en el tratamiento al fenómeno migratorio en el discurso político de López Obrados?

- ¿Qué enfoque prevalece sobre política migratoria en el discurso político de AMLO?

El estudio en cuestión se concentra en develar las condicionantes en la producción e interpretación del discurso. La perspectiva discursiva profundiza en el análisis del contexto y cuestiones propias en el tratamiento al tema migratorio y su práctica política. Los referentes de la investigación se vinculan a trabajos recientes de Durand ${ }^{3}$ y Rodríguez Arrieta ${ }^{4}$ para la búsqueda de elementos en el discurso político sobre la migración, con el fin de detectar los marcos de referencia sobre los cuales se desarrollan los programas de gobierno.

En este punto, se asume como marco de referencia el argumento discursivo en la proyección política de López Obrador, en su proceso de candidatura y actual gestión. Se consideró el periodo de campaña presidencial en la muestra seleccionada, aunque se enfatiza en los meses de administración de diciembre 2018 a enero 2020. Se tuvieron como referencia los tópicos de interés en su discurso político; la aplicabilidad de esta distinción analítica recurre a las conferencias de prensa matutinas como unidades de análisis.

\footnotetext{
2 Zapata-Barrero, Ricard, Fundamentos de los discursos politicos en torno a la inmigración, Madrid, Trotta, 2009.

${ }^{3}$ DuRAnd, JoRge, "Política migratoria: entre el discurso, la práctica y la coyuntura" Foro Internacional, vol. 59, núm. 34, 2019, pp. 1023-1047.

${ }^{4}$ Rodriguez Arrieta, José Daniel, "Discursos políticos sobre la inmigración presentes en los programas de gobierno del proceso electoral de Costa Rica 2017-2018", Revista Rupturas, vol. 9, núm. 2, pp. 39-61.
} 
El registro de veinte documentos publicados en versión estenográfica de las conferencias de prensa matutina en el sitio oficial del presidente de México, Andrés Manuel López Obrador, ${ }^{5}$ permitió delimitar el tema migratorio en el discurso político. El criterio de selección expresa la inclusión del fenómeno migratorio en la agenda política de AML0, durante el 2019, como resultado de las tensiones y acuerdos bilaterales entre Estados Unidos y México. El uso del Atlas.ti ${ }^{6}$ permitió la cuantificación de los tópicos de interés en el discurso (análisis de frecuencia) y la elaboración de gráficos para la visualización de los resultados. Por ello, el presente trabajo no pretende aportar una metodología -lo cual precisaría de un mayor análisis y ampliación-, sino mostrar la evolución del discurso político de López Obrador en el tratamiento al tema migratorio, y la condición del migrante como resultado de su gestión y política migratoria.

En el artículo se dedica un espacio a las distinciones entre el migrante objeto y el migrante sujeto como categorías de análisis. Estas distinciones fueron consideradas metodológicamente desde el enfoque del pensamiento político clásico occidental, en especial, desde los conceptos aportados por la filosofía política. Esto debido a que cuenta con una larga tradición que aborda la relación entre sujeto y objeto, entre necesidad y libertad, entre intereses individuales y colectivos, en contextos de relaciones conflictivas.

El despliegue de este enfoque es pertinente para la comprensión del discurso político del actual Gobierno mexicano en la medida en que el propio discurso se muestra deudor del pensamiento liberal avanzado. En el artículo, no se pretende abordar todas las fuentes teóricas e implicaciones presentes en el pensamiento político que fundamentan el proyecto de gobierno de AMLO. Pero, en dicho discurso, la presencia explícita de la distinción entre migrante libre y voluntario (migrante sujeto) y migrante objetualizado por la crisis permite realizar este tipo de análisis (migrante objeto).

El enfoque utilizado permite valorar la respuesta de AMLO y su proyecto de gestión migratoria ante el enfrentamiento, entre la libertad y la necesidad del migrante. La crisis convierte a estos dos aspectos en opuestos, debido a que el individuo o el grupo dominado por la carencia de fuentes de subsistencia no cuenta con la posibilidad de escoger voluntariamente los términos de su movimiento migratorio. Así, la tarea de unificar en una solución sustentable la necesidad y la libertad de los flujos migratorios aparece como una problemática latente en este discurso.

\footnotetext{
${ }^{5}$ Véase el sitio oficial de Andrés Manuel López Obrador. Disponible en: https://lopezobrador.org.mx/

${ }^{6}$ Cuevas Romo Ana, Méndez Valencia, Sergio y Hernández-Sampieri, Roberto, Manual de introducción a Atlas.ti 7, México, Universidad de Celaya-Instituto Politécnico Nacional, 2014.
} 


\section{La migración de tránsito por México hacia Estados Unidos}

La migración de tránsito en México, hacia Estados Unidos, ha dado lugar a formas de sociabilidad sujetas a políticas, programas $^{7}$ y protocolos. ${ }^{8}$ Como bien expresa Domínguez Martín, ${ }^{9}$ el enfoque de la política migratoria no es precisamente un camino, técnica y políticamente, fácil. Coincidimos en que fijar la política migratoria solo desde el diagnóstico de las causas de la migración, sin atender a la agencia de los migrantes, es totalmente incoherente con los principios que rigen la cooperación para el desarrollo.

En particular, el 2014 fue un año clave para analizar la relación entre migración y su desarrollo crítico, entre flujo normal y asimilable por el sistema y movimiento creciente que se identifica con la reactivación del control. El reforzamiento de la vigilancia fronteriza al norte y sur de México constituye una manifestación de la crisis del sistema migratorio Centroamérica-MéxicoEstados Unidos. El tema de la frontera sur ha sido una preocupación del gobierno mexicano, desde la presidencia de Vicente Fox, pasando por Felipe Calderón, Peña Nieto y, ahora, Andrés Manuel López Obrador.

En este orden, "la preocupación deriva del nuevo contexto de relaciones internacionales, en particular de la política del gobierno de la Casa Blanca en materia de terrorismo, narcotráfico y migración”. ${ }^{10}$ Según Villafuerte y García, "la crisis de los niños migrantes de mediados de 2014 revela la profundidad del colapso del sistema migratorio Centroamérica-México-Estados Unidos”. ${ }^{11}$ Ello explica las formas dominantes en la aplicación de medidas antiinmigrantes, manifiestas en deportaciones y detenciones masivas.

El proceso histórico que ha seguido la región en tránsito, de México hacia Estados Unidos, demuestra el carácter sobrevenido e ideologizado ${ }^{12}$ en el uso de la "crisis migratoria”, para exponer el fenómeno en términos generales. Por

\footnotetext{
${ }^{7}$ Plan de desarrollo para el Triángulo Norte de Centroamérica presentado recientemente en Ciudad de México por la Comisión Económica para América Latina y el Caribe (Cepal), de Naciones Unidas.

8 Protocolo de Protección a Migrantes (MPP, por sus siglas en inglés), que permite a Estados Unidos enviar a México a migrantes que entraron al país por territorio mexicano, mientras tramitan sus solicitudes de asilo.

${ }^{9}$ Dominguez Martin, Rafael, "Migración y desarrollo: mitos tóxicos e incoherencia de políticas en la Unión Europea", en Ada Elsa Cabrera Garcia, Gustavo Rodríguez Albor e Ibelis Blanco Rangel (coords.), Migraciones internacionales en el siglo xxı. Un análisis desde una perspectiva crítica, Puebla, Instituto de Ciencias Sociales y Humanidades "Alfonso Vélez Pliego" de la Benemérita Universidad Autónoma de Puebla, 2019, p. 20. Disponible en: http://repositorio.uac. edu.co/handle/11619/3940

${ }^{10}$ Villafuerte Solis, Daniel y Maria del Carmen Garcia Aguilar, "Crisis del sistema migratorio y seguridad en las fronteras norte y sur del México", Revista Interdisciplinar da Mobilidade Humana, año 23, núm. 44 , p. 87.

${ }^{11}$ Villafuerte Solis, Daniel y Maria del Carmen Garcia Aguilar, "Crisis del sistema migratorio y seguridad en las fronteras norte y sur del México", Revista Interdisciplinar da Mobilidade Humana, año 23, núm. 44, p. 93.

${ }^{12}$ Collet, Elzabeth y Le Coz, Camille After the Storm. Learning from the EU Response to the Migration Crisis, Bruselas, Migration Policy Institute Europe, 2018, p. 63.
} 
tanto, el crecimiento acelerado de los flujos migratorios en los últimos años del siglo xx y en las dos primeras décadas del siglo xxI ha impactado en la política.

En esta línea, las prioridades en gestión migratoria se reducen a hechos e intereses económicos. Lo que resulta sintomático es que, "detrás de todas las olas migratorias latinoamericanas siempre existió un detonante económico perfectamente identificable". ${ }^{13}$ De ahí que el tema del tráfico de drogas, la migración centroamericana irregular en tránsito por México, la trata de personas y seguridad han sido asuntos de interés para los países involucrados. El aumento de los flujos migratorios con presencia de desplazamientos por conflictos y un cierto éxodo a partir de la implementación del modelo neoliberal ${ }^{14}$ advierten el crecimiento sostenido de la migración irregular.

Ahora bien, comprender los procesos migratorios y sus trayectorias implica visualizar la violencia a la que son sometidos los migrantes. La presencia de caravanas migrantes de centroamericanos en México, a finales de 2018 y durante el 2019, muestra la violencia que acompaña a estos grupos en sus trayectorias. ${ }^{15} \mathrm{Si}$ bien se analiza la violencia como motivación de la migración, esta ha quedado "oculta" en el discurso político, dado su efecto mediático. En este sentido, la administración de López Obrador ha considerado el fenómeno migratorio a partir de las garantías de inversión económica y social en los países de origen, ante la pobreza y la violencia; así como el trato humanitario a los derechos de los migrantes en territorio mexicano.

Sin embargo, hasta próximos años se podrá observar la efectividad de los países emisores y de México para atender el fenómeno de la migración centroamericana. El cambio discursivo y de acción en la política migratoria no abarca a todos los grupos de poder implicados. Estados Unidos de América, junto con sectores sociales importantes en las naciones que componen el sistema migratorio, no participa con el mismo peso en este cambio de enfoque.

Hoy, el efecto Trump en la agenda mediática de la migración entre México y Estados Unidos está marcado por un discurso xenófobo. ${ }^{16}$ En este escenario, las actitudes en materia migratoria van desdibujando un complejo entramado de percepciones y prejuicios. Mientras, la actual Administración norteamericana

\footnotetext{
${ }^{13}$ Rodriguez Rodriguez, Rogelıo, "Desafíos de México frente al fenómeno migratorio en la segunda década del siglo XXI, un reto como política pública", Revista Interdiciplinaria de Estudios Latinoamericanos, vol. 3, núm. 3, p. 85.

${ }^{14}$ Castillo, Manuel Ángel, "Fronteras, migración y seguridad en México", Alteridades, vol. 15, núm. 30, p. 52.

${ }^{15}$ Cordero Diaz, Blanca laura y Garibo Garcia, Maria Georgina, "Violencias encarnadas: migración de mujeres centroamericanas", en Nayar López Castellanos (coord.), Procesos migratorios en la Centroamérica del siglo XXI, México, UNAM, 2018, pp. 171-194; TorRe-Cantalapiedra, Eduardo, "Violencia, migración y refugio: una mirada reflexiva a contribuciones sobre violencia estructural y movilidad geográfica", Huellas de la Migración, vol. 4, núm. 7, pp. 139-171.

${ }^{16}$ Canales Lizadla, Laura y LizárRaga Salas, Frambel, "El efecto Trump: la migración mexicana en la agenda mediática de la prensa de México y Estados Unidos: La Jornada, El Universal y La Opinión", Revista Interdisciplina, vol. 7, núm.18, p. 128.
} 
ha marcado su política "en un abierto rechazo a la internación de más migrantes hacia su país, convirtiéndose como eje de su política exterior y migratoria la necesidad de construir el muro fronterizo, generando un discurso político antimigratorio". ${ }^{17}$ Por tanto, el discurso político presente en las agendas de los gobiernos acerca de la migración muestra la visión y gestión del fenómeno por parte de los principales decisores a nivel de nación, región y a escala internacional.

\section{Noción del migrante sujeto y del migrante objeto en el discurso político}

Otro principio que defiende constantemente el discurso presidencial mexicano es la noción del migrante sujeto y del migrante objeto. En términos teóricos, estas le permiten al gobierno mexicano clasificar entre al menos dos tipos de migración: una de ellas consustancial a la dinámica migratoria; la otra, propia de la normalidad.

En este sentido, para el gobierno mexicano, el flujo que se caracteriza por un migrante-objeto, forzado por las dificultades y la falta de alternativas a la búsqueda de sueños, de justicia y mejoramiento económico fuera de su país, es el flujo incontrolable y crítico. Este migrante objeto se ve determinado por una precariedad originaria de sus condiciones de vida, matizado por la desesperación y el desorden, por el riesgo de un tránsito al margen de la legalidad. Se trata de un ente al margen de su propia voluntad, identificable como víctima-participante de la crisis:

El fenómeno migratorio no surge de la nada, es originado por las carencias materiales y la inseguridad en los países centroamericanos y en sectores y regiones marginadas de México, en donde hay seres humanos que necesitan emprender todo un peregrinar para mitigar su hambre y su pobreza o para preservar sus vidas. ${ }^{18}$

Por su parte, el flujo identificable con la "normalidad" y la "regulación” se caracteriza por un migrante totalmente voluntario, capaz de cambiar sus condiciones aceptables de vida por otras mucho mejores, pero basándose en la legalidad de su tránsito, en el respeto a las normas establecidas y en la

\footnotetext{
${ }^{17}$ Rodriguez Rodriguez, Rogelo, "Desafíos de México frente al fenómeno migratorio en la segunda década del siglo xxl, un reto como política pública", Revista Interdiciplinaria de Estudios Latinoamericanos, vol. 3, núm. 3, p. 94.

${ }^{18}$ Discurso de Andrés Manuel López Obrador en el acto en defensa de la dignidad nacional y en favor de la amistad con Estados Unidos, en Tijuana, Baja California, 8 de junio, 2019.
} 
seguridad propia. A tono con ello, AMLO apunta: "Lo más eficaz y lo más humano es enfrentar el fenómeno migratorio combatiendo la falta de oportunidades de empleo y la pobreza, para lograr que la migración sea opcional, no forzada". ${ }^{19}$

Este esfuerzo por concientizar al migrante como sujeto político y de derecho conlleva un grupo de dificultades teóricas y prácticas que el gobierno mexicano ha tenido que visualizar. A grandes rasgos, las opciones principales de este discurso han sido la aplicación de la legalidad, el perfeccionamiento de los trámites y normativas que permitan ordenar y controlar el fenómeno, así como la inversión para el desarrollo de puestos de trabajo y condiciones de vida.

Sin embargo, desde el migrante con antecedentes delictivos, pasando por los grupos más vulnerables como los niños y las mujeres, la estrategia de contención aunada al respeto de los derechos humanos tensa al máximo el marco referencial del discurso político. Sobre todo, porque se trata de ciudadanos y de personas; lo primero obliga a respetar múltiples legalidades (país de origen, de tránsito y de destino), lo segundo remite a normas de órganos extranacionales como la onU y sus comisiones de derechos humanos de diferentes niveles.

La negativa de México a convertirse en tercer "país seguro" revela los límites y las tensiones de esta sintesis entre interés nacional, doctrina de derechos humanos y multilateralismo. Este significado emerge con la idea de que el proyecto de AMLO tiene un enfoque mucho más humanista y ponderado de la crisis, pero sigue considerándose un intermediario y no un protagonista del conflicto. Así, es un intermediario dispuesto a mediar y contribuir a la solución de un problema que se origina más allá de sus fronteras. Por ello, su respuesta y capacidad cooperativa tendrán los límites usuales, aunque flexibles, en su caso, a los intereses del Estado-nación.

La propia sociedad civil mexicana y sus múltiples tendencias políticas se muestran como grupos de presión que, sin eliminar la capacidad de maniobra del gobierno, fijan límites infranqueables para su radio de acción global sobre 190 el problema. La prensa y otros medios de comunicación sociopolítica insisten continuamente en la responsabilidad del Estado mexicano para con sus ciudadanos. A la postre, en Estados Unidos, la comunidad de migrantes mexicanos supera en número a la de los demás países de la región.

\footnotetext{
${ }^{19}$ Discurso de Andrés Manuel López Obrador en el acto en defensa de la dignidad nacional y en favor de la amistad con Estados Unidos, en Tijuana, Baja California, 8 de junio, 2019.
} 
Esta comunidad también está sujeta al discurso antiinmigrante, xenófobo y racista de la actual Administración norteamericana. Por tanto, las implicaciones de manifestaciones xenófobas emerge como asunto y oportuna aclaración en el discurso político de AML0, ante los hechos ocurridos en Texas y los síntomas visibles de rechazo a los migrantes o extranjeros.

La estrategia mexicana ante el sistema migratorio de Centroamérica-México y Estados Unidos se ve condicionada por las capacidades limitadas del proyecto de nación para resolver problemas del sistema mundo capitalista. Al mismo tiempo, la relación política cualitativamente superior entre la comunidad migrante mexicana en Estados Unidos y el Estado mexicano permite prever que, a largo plazo, este asunto atraerá gradualmente el foco de atención. Por el momento, la política de López Obrador ante el problema intenta llevar a sus posibilidades plenas, dentro de dichas limitantes, el esfuerzo de cooperación con países implicados; medio para sobrepasar el ámbito nacional ante crisis que son transnacionales.

\section{El tema migratorio en el discurso y acción política del gobierno de Andrés Manuel López Obrador}

El discurso y la acción política del gobierno de López Obrador reconocen que el tema migratorio viene a catalizar espacios de fricción en la larga historia de relaciones contradictorias y codependientes -incluso, mutuamente ventajosasentre México y Estados Unidos. La relación de México con Estados Unidos y los países latinoamericanos, en materia migratoria, se revela como marco determinante para el discurso de la actual Administración mexicana.

A partir del 2014, se vuele sintomático en el discurso político de Obrador la problemática migratoria como un asunto que requiere de la cooperación para el desarrollo. Se trata de un tema latente en su discurso de campaña y que prevalece en el debate público, por su prioridad para la política y gestión de gobierno. En términos ilustrativos, la fluctuación en el tratamiento al tema desde su visión se representa en el gráfico siguiente: 
Gráfico 1. Tratamiento al tema migratorio en el discurso político de AMLO según su frecuencia en los meses de julio 2014 hasta febrero 2020

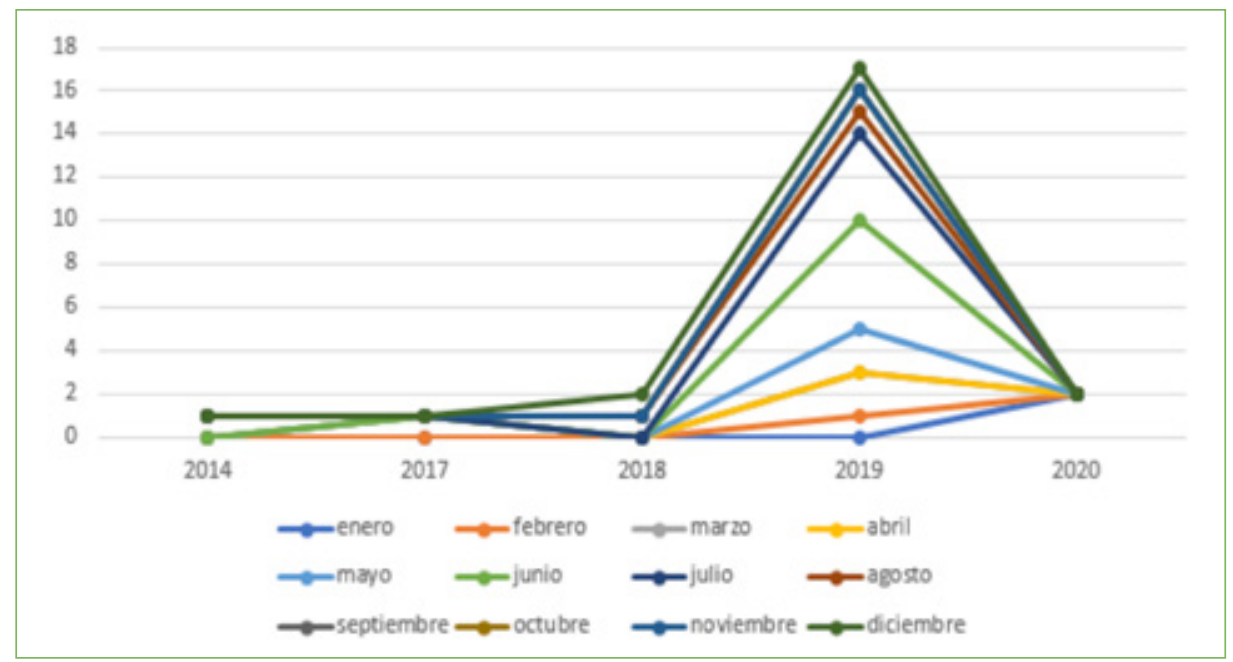

Fuente: Elaboración propia con información extraída de las conferencias de prensa matutinas y discursos de Andrés Manuel López Obrador.

El comportamiento del tema migratorio en el periodo de 2014 al 2018 muestra, en términos ideológicos, el carácter incipiente de este asunto, en su práctica política y en la consolidación de su liderazgo. Sin embargo, en calidad de presidente del Consejo Nacional del Movimiento Regeneración Nacional (Morena), ${ }^{20}$ al referirse al tema migratorio y los efectos de la política estadounidense, declaró que: "Obama debería de apoyar sobre un convenio de cooperación para el desarrollo y cumplir con su compromiso de campaña. No solo eso, es el presidente de Estados Unidos que más ha deportado a migrantes, va a pasar a la historia como un presidente racista, que discrimina a latinos". ${ }^{21}$

En este escenario de formas políticas cuestionables para gestionar la migración, resalta el papel de México como país auspiciador de las sesiones preparatorias de la Conferencia Intergubernamental..$^{22}$ Durante la inauguración, la representante especial del secretario general de la onU para la Migración Internacional, Louise Arbour, destacó que: “el Pacto Global para la Migración es una oportunidad para

\footnotetext{
${ }^{20}$ Con fecha 9 de julio, 2014, se emitió la Resolución del Consejo General del Instituto Nacional Electoral, sobre la solicitud de registro como partido político nacional presentada por Movimiento Regeneración Nacional.

${ }^{21}$ Conferencia de prensa en Tapachula, Chiapas, 25 de julio, 2014.

${ }^{22}$ Reunión preparatoria en Puerto Vallarta, México los dias 4, 5 y 6 de diciembre 2017 con la participación de los Estados miembros de la onu, en la cual se adoptararon acuerdos para el Pacto Mundial para una Migración Segura, Ordenada y Regular en 2018.
} 
reorientar la narrativa -a menudo tóxica- contra las personas migrantes hacia una narrativa más precisa que reconozca el apoyo extraordinariamente positivo y está preparado para dirigirse a los cambios en una manera seria y realista”. ${ }^{23}$

Así, es relevante el mensaje de López Obrador, en su recorrido por ciudades de Estados Unidos:

El propósito de esta gira es expresar nuestro apoyo, nuestra solidaridad con ustedes, los migrantes, los que por necesidad, no por gusto, han abandonado sus pueblos, sus lugares de origen para venirse a buscar la vida con trabajo honrado en Estados Unidos y que ahora, por lo que todos sabemos, están siendo víctimas del acoso y de la persecución [...] La migración es la prueba más clara y dolorosa del carácter excluyente del modelo neoliberal [...] En esta paradójica y amarga realidad, mezcla de heroísmo y desdicha, ustedes deben ahora enfrentar una nueva circunstancia: la amenaza y la persecución de migrantes anunciada por Donald Trump. ${ }^{24}$

Como bien se ha expuesto, desde el 2014 hasta la fecha, López Obrador ha incluido la migración como tema emergente en su agenda política. En consecuencia, el proyecto de nación 2018-2024 refleja la migración como política de gobierno. Ello implica un área específica en la coordinación con países estratégicos y una oportunidad para la acción multilateral. Tales acciones se integran con los objetivos regionales, como resultado del nuevo diálogo con América del Norte, en defensa de los mexicanos y la cooperación.

Respecto a los retos migratorios del gobierno mexicano, en el proyecto de nación, se acentúan las perspectivas; acciones de política migratoria transversal; protección y defensa de los derechos humanos de los migrantes; evaluación y monitoreo de la política migratoria. El propio documento declara la actuación del gobierno para atender las causas de la migración de manera integral:

[...] insistirá en que la migración no es un problema en sí, sino un fenómeno inherente a la humanidad misma. La migración no puede ni debe ser criminalizada. Para encararla de manera adecuada, se deben abordar sus causas profundas como la pobreza, la falta de oportunidades, la inseguridad, el cambio climático y los conflictos. ${ }^{25}$

\footnotetext{
${ }^{23}$ Centro de Noticias onu, 4 de diciembre, 2017.

${ }^{24}$ Mensaje de Andrés Manuel López Obrador, presidente del Comité Ejecutivo Nacional de Morena, en Nueva York, Estados Unidos, 13 de marzo, 2017.

${ }^{25}$ Proyecto de Nación 2018-2024, p. 89.
} 
Ello produce un giro en el tratamiento al tema migratorio, tras la tendencia creciente de los flujos migratorios hacia México y Estados Unidos, durante los meses de enero a diciembre 2019. Por tanto, ocupa interés en la esfera pública y en la agenda mediática y política del actual gobierno mexicano (veáse el gráfico 2).

Gráfico 2. Tópicos de interés en el discurso político de AMLO según su frecuencia durante los meses correspondientes al 2019

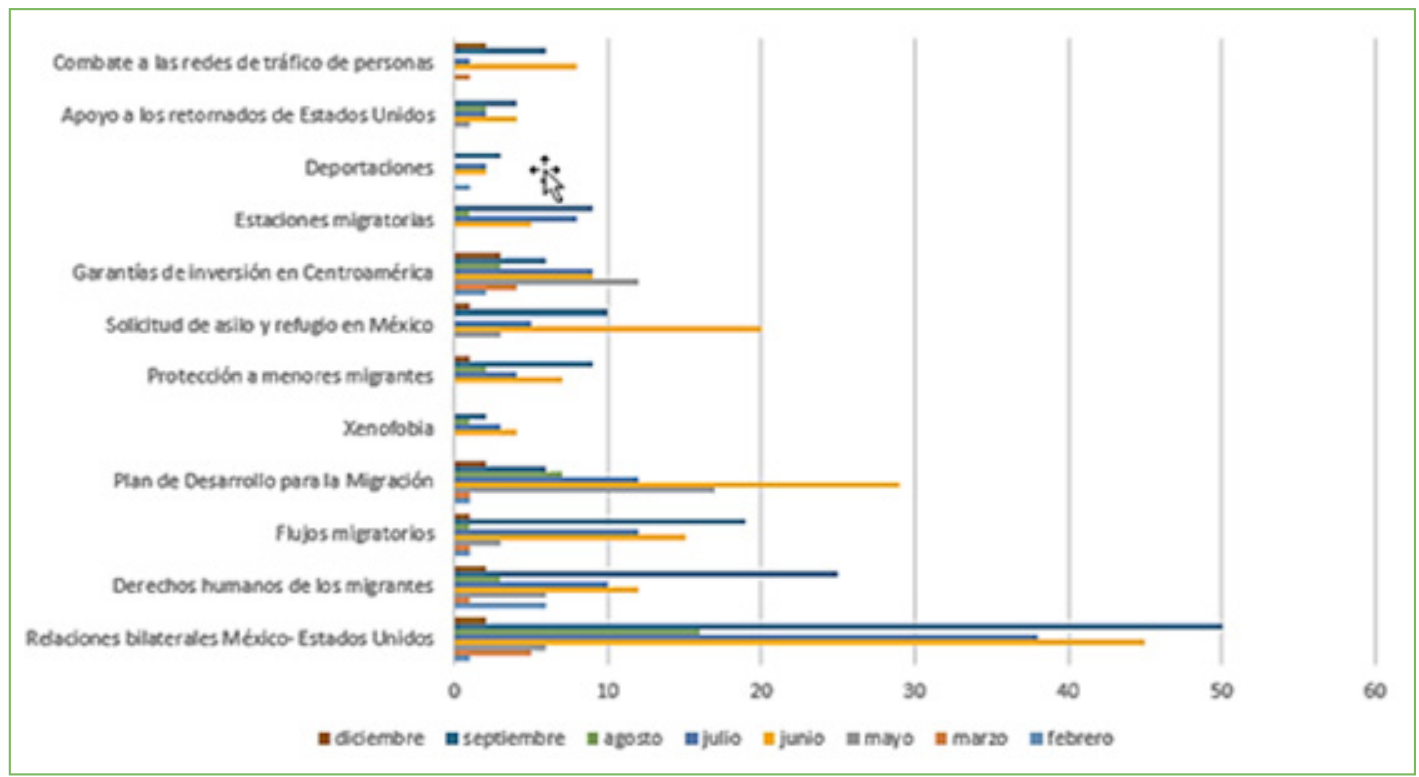

Fuente: Elaboración propia con base en las dieciocho conferencias de prensa matutinas de Andrés Manuel López Obrador sobre el tema migratorio durante el 2019.

En particular, la intención de un acuerdo migratorio entre Estados Unidos y México figura en el discurso político desde febrero 2019. Para la fecha, comienza el ascenso de eventos de repatriación de mexicanos desde Estados Unidos, con lo cual fueron afectadas 211258 personas, de enero a diciembre de 2019. ${ }^{26}$ Los datos muestran la urgencia de establecer un programa de apoyo a los paisanos migrantes en respuesta a la política estadounidense.

\footnotetext{
${ }^{26}$ Unidad de Política Migratoria, Registro e Identidad de Personas, Segob, con base en el Boletín Mensual de Estadisticas Migratorias 2018-2019.
} 
En el mes de marzo se dieron a conocer las conversaciones con Estados Unidos para un posible acuerdo migratorio bajo el principio de garantías de inversión para los países de Centroamérica y México. No obstante, los meses de marzo, mayo y octubre, según las estadísticas de 2019, resultaron en más de diecinueve mil repatriados de origen mexicano. ${ }^{27}$

Los meses de mayo y junio corresponden al periodo de conversaciones y firma del acuerdo migratorio México-Estados Unidos. ${ }^{28}$ Una lectura de los discursos, informes y conferencias de prensa del gobierno mexicano permite, a su vez, visualizar su esfuerzo por dar continuidad a una tendencia universal de la diplomacia y de la política exterior de ese país a lo largo de su historia. Esto es, el mantenimiento de la independencia y de un criterio propio para dicha política, que exige un análisis objetivo de los fenómenos conflictivos y sus causas. A esta tendencia corresponde una línea de acción que acepta la posibilidad de diferir en muchos puntos con la postura de sus aliados o principales socios comerciales, como es el caso paradigmático de Estados Unidos.

Este principio de independencia alcanza su contrapeso en un segundo presupuesto que retoma la importancia del realismo político en el discurso gubernamental mexicano: el reconocimiento de la influencia que sus aliados y socios tienen en la toma de decisiones. Más allá de las presiones explícitas de una determinada Administración norteamericana, México no oculta la importancia que los intereses de su principal socio comercial tienen en el derrotero que se puede tomar ante el tema migratorio.

Este intento de síntesis entre independencia y realismo político, según palabras del propio López Obrador, se inclina a ese punto medio en el que: "Se requiere de diplomacia, de convencer, de persuadir, sobre todo al gobierno de Estados Unidos, para que podamos [...] hacer realidad este enfoque que nos conviene a todos" ${ }^{29}$ Tal postura podría resumirse en no ceder abiertamente a las presiones del socio dominante, pero tampoco pasar por alto sus intereses, pues ello conduciría al antagonismo. Así, se concentra en encontrar la estrategia que conduzca a una situación de ganar-ganar.

Si Estados Unidos considera prioridad detener la migración descontrolada que afecta sus relaciones políticas internas y sus resultados electorales, México hace suya esa exigencia y es capaz de invertir cientos de millones

\footnotetext{
${ }^{27}$ Unidad de Politica Migratoria, Registro e Identidad de Personas, Segob, con base en el Boletín Mensual de Estadísticas Migratorias 2018-2019.

${ }^{28}$ Con fecha 7 de junio, 2019, México y Estados Unidos firmaron un acuerdo para reducir el flujo de migrantes centroamericanos.

${ }^{29}$ Versión estenográfica de la conferencia de prensa matutina del presidente Andrés Manuel López Obrador, 20 de mayo, 2019.
} 
de dólares en un plazo de diez años, en un esfuerzo inédito para resolver un problema que afecta a su vecino del norte y a los países emisores. Las críticas de los nacionalistas a esta estrategia son inevitables, todo parece indicar que esta doctrina conduce a que la nación se convierta en instrumento de una potencia extranjera.

Ante estas críticas, la respuesta de López Obrador y de su esfuerzo gubernamental muestran la intención de integrar conceptualmente ideas del nacionalismo, de la doctrina de la seguridad nacional con nociones provenientes del humanismo o de la cooperación internacional, emanadas de instituciones como la onu, la Cepal y otros organismos multilaterales. No obstante, en el interior de este enfoque humanista, reaparece una y otra vez el utilitarismo, el cual resulta un conjunto de nociones asentadas en el objetivo de preservar el funcionamiento real de la economía mexicana.

En este último punto, la utilidad primaria se desprende de la idea de que todo lo que permita mantener o mejorar la obtención de recursos materiales, para la transformación social, debe preservarse por su carácter estratégico. López Obrador se distancia del "economicismo" tecnocrático neoliberal, tratando, a su vez, de no obviar las condiciones de existencia-sostén material de su proyecto político.

En ese sentido, López Obrador propone un paradigma de acción política que flexibiliza el horizonte de significado y de legitimidad del Estado-nación, basado en el vínculo deber-derecho, entre el gobierno y sus ciudadanos. Desde este enfoque, México gana la posibilidad de evitar un conflicto con su principal socio en el mundo, mientras aplica las estrategias más avanzadas de colaboración con países afectados. Desde el enfoque del gobierno mexicano,evitar la confrontación significa no tener que pagar un costo comercial que superaría decenas de veces el monto de lo invertido por México en su estrategia de colaboración, inversión para el desarrollo y contención de las migraciones.

En este aspecto, Obrador declara que "estamos hablando de un superávit a favor de México de alrededor de setenta mil millones de dólares” ${ }^{30} \mathrm{y}$, con ello, "se evitó la posibilidad de una crisis económica, financiera". ${ }^{31} 0$ sea, ambos actores políticos fijan los límites: "México tiene un límite, el 80\% de nuestra economía está vinculada a la de Estados Unidos, pero Estados Unidos también

\footnotetext{
${ }^{30}$ Versión estenográfica de la conferencia de prensa matutina del presidente Andrés Manuel López Obrador, 21 de junio, 2019.

${ }^{31}$ Versión estenográfica de la conferencia de prensa matutina del presidente Andrés Manuel López Obrador, 12 de junio, 2019.
} 
tiene un límite, porque 15\% de la economía más grande del mundo depende de la relación con México". ${ }^{32}$

Otro aspecto que se recalca en este discurso sobre la estrategia diplomática es que, con ella, el país alcanza prestigio y protagonismo internacional, al ser el que más aporta a la solución de la crisis migratoria. Aquí, se reactiva, nuevamente, la idea de México como sujeto político independiente, con personalidad y peso propio en las relaciones internacionales. En palabras de López Obrador, el país "inauguró un método nuevo, distinto, para enfrentar el fenómeno migratorio. Es una luz [...] que se enciende desde México, desde Centroamérica, para alumbrar en todo el mundo".33

Lo explicado hasta el momento muestra que, ante varios problemas medulares, el pensamiento y el discurso político de Obrador arriesgan el intento de unificar elementos tradicionalmente contradictorios. Por un lado, consiste en defender los intereses de México sin negar el peso de los intereses extranjeros, en especial los norteamericanos; simbiosis entre utilitarismo y patriotismo, entre nacionalismo y presupuestos de cooperación multilateral. Por otro lado, implica la negación rotunda a la militarización y rechazo al uso determinante de la fuerza, para, al final crear una fuerza pública de origen militar con tareas de protección a los derechos humanos.

El propio presidente mexicano refleja en sus palabras la tensión conceptual y los riesgos de su paradigma cuando declara: "La política es el equilibrio [...] entre principios y eficacia. No se puede hacer política solo con principios, como tampoco se puede hacer política solo buscando la eficacia y sin principios. Es el equilibrio y hay fronteras, uno sabe hasta dónde se puede llegar". ${ }^{34}$

Tal proceso de conciliación se concreta en el diseño e implementación del Plan de Desarrollo para la Migración 2019. En efecto, durante el mes de mayo, el debate público se centra en el cumplimiento de las metas de inversión, a través de los programas vigentes. Además, sobre el principio de una política que busca la eficacia, se exponen asuntos relativos al promedio de deportaciones masivas por día; la política de retorno y el discurso de xenofobia hacia los migrantes centramericanos y mexicanos.

Hechos como la reducción del flujo migratorio se derivan de políticas gubernamentales con fundamento en la Ley Mexicana de Migración y disposiciones

\footnotetext{
${ }^{32}$ Versión estenográfica de la conferencia de prensa matutina del presidente Andrés Manuel López Obrador, 21 de junio, 2019.

${ }^{33}$ Versión estenográfica de la conferencia de prensa matutina del presidente Andrés Manuel López Obrador, 21 de junio, 2019.

${ }^{34}$ Versión estenográfica de la conferencia de prensa matutina del presidente Andrés Manuel López Obrador, 21 de junio, 2019.
} 
constitucionales. A su vez, tal reducción constituye un indicador para medir el alcance del sistema de gestión migratoria. Su evaluación durante los tres meses del acuerdo migratorio denota el promedio de reducción del flujo migratorio como un dato de interés para la opinión internacional. Además, implicó eventos de deportación y retorno asistido ${ }^{35}$ para un total de 123239 extranjeros devueltos de enero a diciembre de $2019 .{ }^{36}$ México deportó a 98.6\% de los migrantes que entraron al país, respecto a las 179971 personas extranjeras en condición de estancia irregular que fueron alojadas en las distintas estaciones y estancias migratorias. ${ }^{37}$ De acuerdo con los datos, se puede ver que la reducción del flujo migratorio como política de país responde a eventos de deportación como mecanismo regulador de movilidad.

La evaluación de resultados a partir del acuerdo migratorio México-Estados Unidos se estructura por etapas en el marco de los 45 y 90 días, a partir del 7 de junio del 2019. Por ello, los momentos de evaluación y balance de los puntos fijados en el acuerdo se corresponden con los meses de mayor frecuencia en el tratamiento del asunto migratorio (junio, julio y septiembre) del 2019. Ello representa $61.11 \%$ de las veinte conferencias de prensa matutinas y discursos realizados sobre el tema migratorio en el periodo analizado.

La necesidad del reconocimiento mundial a la política exterior de México y la asunción de una política migratoria "distinta" dirigen la atención a la Secretaría de Relaciones Exteriores. El tema de los derechos humanos de los migrantes y las denuncias sobre sus posibles violaciones demandaron la participación de organismos internacionales, organizaciones de la sociedad civil y gobiernos.

La presentación de protocolos para la atención a menores no acompañados en el territorio nacional, así como la transparencia en las estadísticas propias de la política de asilo y refugio como país de origen, tránsito y destino, ocuparon los balances emitidos en el curso de estos meses. En este orden de prioridad, las acciones de protección a migrantes que efectuaron los Grupos

${ }^{35}$ Eventos de deportación: se refiere a eventos de migrantes retornados a su país de origen, según lo previsto en los artículos 111, 115 y 122 de la Ley de Migración, y de los artículos 242 y 243 de su reglamento, previo proceso administrativo de presentación, según lo establecido en el artículo 99 de la misma ley. Eventos de retorno asistido: se refiere a eventos de migrantes de 18 años o más, que solicitaron el beneficio de retorno asistido para ser regresados a su pais de origen, según lo previsto en los artículos 111, 115, 118 y 119 de la Ley de Migración, y del artículo 193 de su reglamento, previo proceso administrativo de presentación, según lo establecido en el artículo 99 de la misma ley. Eventos de retorno asistido de menores: se refiere a eventos de menores de 18 años devueltos a su pais de origen, según lo previsto en los artículos 111, 112, 115 y 120 de la Ley de Migración, y del artículo 193 de su reglamento.

${ }^{36}$ Unidad de Politica Migratoria, Registro e Identidad de Personas, Segob, con base en el Boletín Mensual de Estadisticas Migratorias 2018-2019.

${ }^{37}$ Datos publicados en nota de prensa el 7 de enero, 2020, por Susana Guzmán en el Financiero según las Estadísticas de Segob (enero-diciembre 2019). 
Beta, ${ }^{38}$ de enero adiciembre de 2019, incluye a migrantes rescatados (2796) y migrantes orientados (229 458) para un total de 232254 de migrantes en estado de riesgo. ${ }^{39}$

La primera semana de junio abre el tema migratorio con la firma del acuerdo entre Estados Unidos y México. Al respecto, López Obrador reiteró: "fue un buen acuerdo, pedirle a todos los mexicanos que actuemos con humanismo, nada de xenofobia, nada de campaña contra los migrantes"..$^{40}$ En este contexto de la "decidida postura de mantener una política de respeto y buena vencidad" y la política de principios de no injerencias, así como la declaración de "cumplir puntualmente los compromisos, reforzar nuestra frontera, aplicar la ley y respetar los derechos humanos" afianzan la política exterior de México.

Lo anterior se reafirma desde el "compromiso de proteger los derechos humanos porque por encima de las fronteras está la fraternidad universal. La justicia no tiene fronteras y tenemos que garantizar que haya justicia para cualquier ser humano". ${ }^{41}$ El principio de justicia se adhiere a su discurso como valor ante los conflictos y reacciones latentes en la actual coyuntura migratoria.

Por otra parte, el discurso de Obrador busca esquivar la simple identidad entre absoluta libertad de movimiento y legitimidad. Ello le permite posponer el espinoso problema de la condición esencial de Estados Unidos como país de destino. Sin embargo, la compleja relación con su principal socio comercial y los componentes racistas o xenófobos del enfoque norteamericano colocan a México ante varias encrucijadas teóricas y prácticas.

Resulta imposible negar que la dinámica económica de Estados Unidos continuará siendo un fuerte atractivo para la migración hacia su territorio. Por ello, la sociedad norteamericana, a pesar de sus inmensas contradicciones, seguirá siendo un imán para los flujos migratorios de la región. La

\footnotetext{
${ }^{38}$ Los Grupos Beta son grupos de protección a migrantes, creados en México desde 1990, con el fin de proteger la integridad física, rescatar y ayudar a los migrantes, con independencia de su nacionalidad y condición migratoria. Realizan acciones de orientación y prevención; rescate y salvamento; asistencia social y humanitaria, así como de asesoría jurídica.

${ }^{39}$ Migrantes rescatados: incluye a migrantes que fueron retirados de una situación o estado de riesgo, independientemente del tipo de asistencia u orientación que se le brinda. El rescate pudo llevarse a cabo en cualquier escenario (río, desierto, vías de tren, túneles o áreas urbanas). Migrantes orientados: incluye a migrantes que recibieron orientación acerca de los riesgos físicos a los que se encuentran expuestos, así como de sus derechos humanos. La orientación es brindada de manera verbal; además, se les pudo haber entregado una cartilla o tríptico con la información antes mencionada, sin importar su nacionalidad o situación migratoria, según la Unidad de Política Migratoria, Registro e Identidad de Personas, Segob, con base en el Boletín Mensual de Estadisticas Migratorias 2018-2019.

${ }^{40}$ Versión estenográfica, "Sembrando vida", Plan de Desarrollo para la Migración, en Tapachula, Chiapas, 20 de junio, 2019.

${ }^{41}$ Versión estenográfica, "Sembrando vida", Plan de Desarrollo para la Migración, en Tapachula, Chiapas, 20 de junio, 2019.
} 
participación de Estados Unidos en las inversiones para el desarrollo centroamericano -según las declaraciones de México- deberá ser significativa y correspondiente a su carácter de principal país interesado en crear un flujo ordenado y legal de migrantes.

De esta manera, la respuesta teórica y práctica del actual gobierno mexicano se inclina a la solución de cuestiones inmediatas y perentorias, dejando para el mediano plazo la solución de cuestiones más complejas como la posibilidad de que Estados Unidos cambie algunos de sus enfoques racistas y anti-migrantes. No obstante, se perciben elementos viables en la propuesta mexicana, encaminada a potenciar la síntesis adecuada entre necesidad y libertad en el sujeto migrante.

Si la actual situación es de enfrentamiento entre necesidad y libertad, para López Obrador tampoco es viable una abstracta y pura identidad que legitimaría un flujo descontrolado por México hacia Estados Unidos. El gobierno de Obrador reconoce que México no puede ser un espacio vaciado de legalidad, que el país tiene compromisos jurídicos y políticos para con los migrantes y para con los países implicados.

La preocupación que suscita el crecimiento del flujo migratorio hacia Estados Unidos corrobora el dato de los 521000 migrantes que ingresaron por la frontera sur con intención de llegar al país del norte; 159359 son menores de edad y 43875 viajaron solos. ${ }^{42}$ Este auge en el flujo migratorio obliga a enfatizar en la aplicación inmediata del programa de desarrollo de la Cepal para impulsar las actividades productivas y crear empleos en Centroamérica y en el sur-sureste de México.

Las conferencias de prensa matutinas, como espacio de interacción social entre López Obrador y los respresentantes de los medios de comunicación, permite que emerjan temas poco frecuentes en el debate. Así, las condiciones de los albergues y estaciones migratorias habilitadas constituyen un tópico en el tratamiento al fenómeno migratorio, que surge como resultado de esa interacción a partir de junio 2019. Asimismo, resalta la información de secuestros masivos de migrantes tras ser retornados de Estados Unidos a México.

En este sentido, las trayectorias de migrantes muestran indicadores observables de la presencia de redes de tráfico de personas. Para la tercera semana de junio, el pronunciamiento de las autoridades mexicanas está dirigido a impedir que el tráfico de personas siga ocurriendo y a declarar la no tolerancia a las actividades asociadas al tráfico de personas. Cabe decir que este, a pesar de ser

${ }_{42}$ Discurso de Andrés Manuel López Obrador en el acto en defensa de la dignidad nacional y en favor de la amistad con EEUU, en Tijuana, Baja California, 8 de junio 2019. 
un tema tan sensible a los efectos de la movilidad social, ocupa un nivel de frecuencia muy bajo.

A finales de julio, se retomó el tema ante la problemática del inmenso flujo de menores; las pésimas condiciones de las estaciones migratorias; el negocio ilícito en el tráfico de personas; el debate sobre México como posible "tercer país seguro", y la corresponsabilidad de Estados Unidos y México para la aplicación del Plan de Desarrollo Integral en Centroamérica preparado por la Cepal. Asimismo, se recurrió a la información sobre la cantidad de deportados y repatriados; reportes de los programas de inversión social en Centroamérica; cifras de reducción del flujo migratorio para la fecha; datos de los migrantes retornados que trabajan al norte del país, y cifras de solicitudes de asilo y refugio.

El compromiso exigible frente a los Estados Unidos en respaldo al punto 4, contraído en el acuerdo migratorio Estados Unidos-México, denota la corresponsabilidad en los programas de desarrollo. Aumentar la inversión en Centroamérica alude a que "no es un gasto, es inversión, es atender las necesidades". ${ }^{43} \mathrm{El}$ mes de junio fijó los propósitos del sistema de gestión migratoria planteado en aras de regular el flujo migratorio. Asimismo, se hicieron comunicables las responsabilidades de la Secretaría de Relaciones Exteriores en las acciones de migración y respeto a los derechos humanos.

En este sentido, ciertos aspectos del enfoque de López Obrador permiten definir la continuidad y las diferencias, entre su etapa de aspirante a la presidencia y su actual postura como mandatario de la nación. Destacan como principios de continuidad su consideración sobre las raíces económicas y sociales del problema migratorio, la necesidad de políticas de inversión social, el impacto negativo del racismo y la xenofobia en el tratamiento a las migraciones, y la importancia de acuerdos entre México, Estados Unidos y otros países latinoamericanos, como marco para una solución de fondo a un proceso que resulta multifactorial y de alcance internacional. El siguiente gráfico expone la estabilidad y caída de temas frecuentes en el tratamiento al fenómeno migratorio dentro del discurso político de López Obrador (véase el gráfico 3).

${ }^{43}$ Versión estenográfica de la conferencia de prensa matutina del presidente Andrés Manuel López Obrador, 11 de junio, 2019. 
Gráfico 3. Evolución de los principales tópicos de interés en el tratamiento al tema migratorio en el discurso político de AML0, según su frecuencia

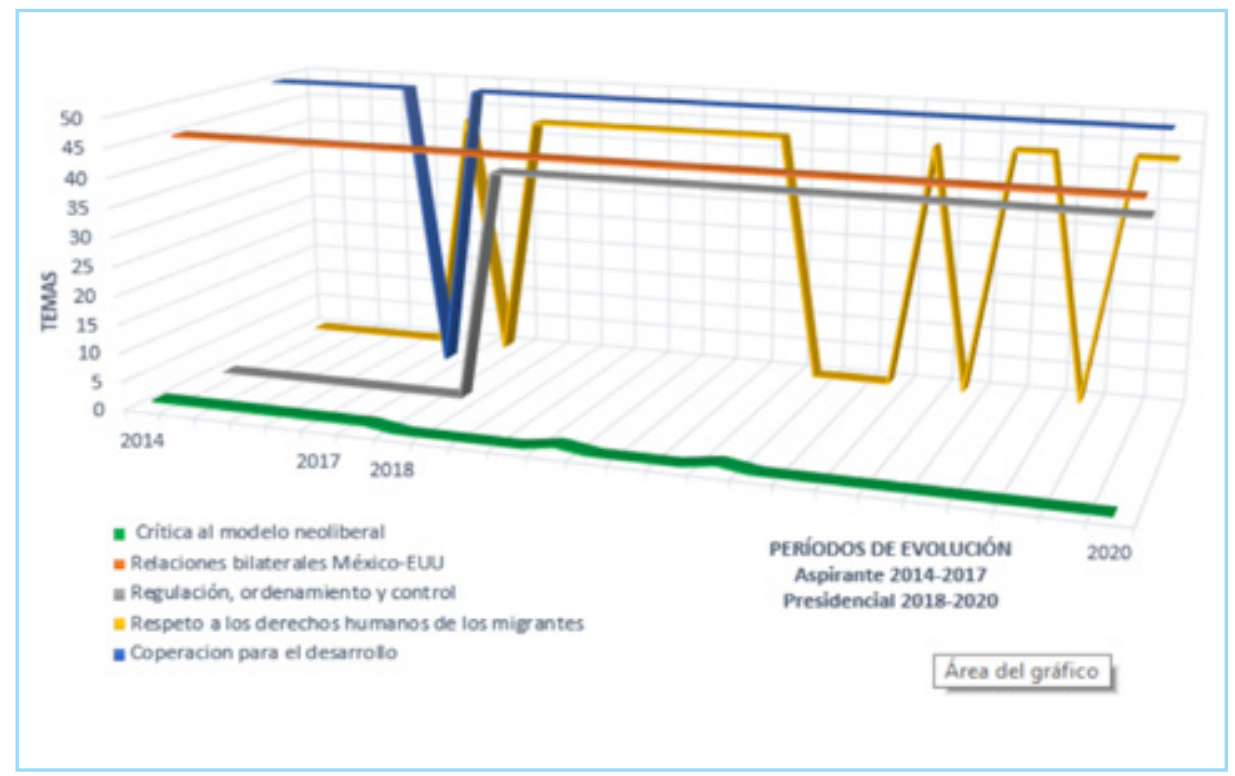

Fuente: elaboración propia con datos extraídos de las conferencias de prensa matutinas, discursos y mensajes de Andrés Manuel López Obrador sobre el tema migratorio en el periodo de 2014 hasta enero, 2020.

En el discurso de López Obrador como presidente, la crítica que anteriormente se había realizado al neoliberalismo se transforma en referencia general a las condiciones económicas de fondo, sin mención a modelos políticos específicos. Esta mutación se vincula con la necesidad de atenuar posibles puntos de tensión con los gobiernos implicados. Ello se desprende de un principio reconocido públicamente por López Obrador de que "la política se inventó, entre otras cosas, para evitar la confrontación". ${ }^{44}$ Esto muestra las peculiaridades del discurso sobre el tema migratorio, pues, si en lo tocante a la realidad interna de México se mantiene el rechazo abierto de Obrador al modelo neoliberal, este ataque se torna sutil o queda oculto en sus proyecciones sobre el problema migratorio.

\footnotetext{
${ }^{44}$ Versión estenográfica, "Sembrando vida", Plan de Desarrollo para la Migración, en Tapachula, Chiapas, 20 de junio, 2019.
} 
Algo similar ocurre con el muy polémico y delicado tema del uso de la fuerza, pues López Obrador heredó un Estado nación con graves problemas para el cumplimiento de uno de sus encargos sociales más definitorios: el estricto control sobre el uso de la fuerza pública y el correspondiente mantenimiento de la seguridad ciudadana.

El proyecto político de AMLO declaró como uno de sus principios fundamentales su ruptura con el autoritarismo, con los excesos en el uso de los cuerpos armados, con el despliegue indiscriminado del armamento de guerra y de los cuerpos represivos contra la ciudadanía o contra las personas en general. Sin embargo, para este proyecto político, una dimensión imposible de negar es la existencia del crimen organizado. Este, en gobiernos anteriores y en la historia reciente de México, ha demostrado su capacidad para colocar a la sociedad y al Estado mexicano en una verdadera crisis de seguridad. Así, la propuesta de la actual Administración mexicana resulta polémica, sobre todo porque se concentra en la creación de un cuerpo especial de seguridad, de origen militar, pero con funciones de protección civil, con normativas y preparación superiores respecto a la preservación de los derechos humanos y de la legalidad nacional e internacional.

El protagonismo de la Guardia Nacional en el tema del control migratorio se produce en el marco de las presiones norteamericanas, nacionales e internacionales hasta convertir el creciente flujo de migrantes hacia Estados Unidos en un verdadero asunto de seguridad nacional para México. En palabras del secretario de Relaciones Exteriores:

La participación de la Guardia Nacional y de elementos que nos van a proporcionar [...] ¿Por qué? Porque lo tenemos que hacer muy rápido. Ahora, la militarización quería decir que vas a ser agresivo, que vas a violentar derechos. No, no es el objetivo. La Guardia Nacional tiene una serie de preceptos en la ley que están aprobados, que se tienen que respetar y la función principal aquí sería migración. [...] Guardia Nacional lo que hace es respaldar las acciones de la autoridad civil que es migración. ${ }^{45}$

El hecho de que, desde junio 2019, la Guardia Nacional (con alrededor de doce mil quinientos elementos) sea la opción del Estado mexicano para la detección y detención de migrantes -integrados en ese entonces por personal del Ejército,

${ }^{45}$ Versión estenográfica de la conferencia de prensa matutina del presidente Andrés Manuel López Obrador, 11 de junio, 2019. 
Marina, Policía Militar, Policía Federal e Instituto Nacional de Migración- ${ }^{46}$ muestra un escenario de militarización de las fronteras. En consecuencia, se recrudece la presencia en la política migratoria de procesos de contención y control, sobre todo de detenciones con considerable impacto en la vida de los migrantes.

Lo que resalta en el discurso político de López Obrador es que, a partir de su principio general que rechaza el uso de la fuerza como instrumento de legitimidad del Estado mexicano, va matizando este presupuesto, a medida que las exigencias del momento lo precisan. Si en la etapa de aspirante pesaba más la crítica total al uso de la fuerza, en la proyección presidencial sobre el tema migratorio, se heredan esas condiciones asociadas que, directa o indirectamente, ignoran el problema.

Lo cierto es que esta proyección de los problemas nacionales e internacionales, incluyendo el flujo migratorio, no pueden resolverse "solamente" con el uso de la fuerza. Pero, este solamente reconoce que, al Estado mexicano -como a cualquier similar en el mundo- le es privativo el uso de la fuerza legítima y controlada. Se trata de una perspectiva que, evidentemente, continúa apostando a mecanismos legales, a la diplomacia, a la inversión social, a las políticas públicas y a la cooperación para la solución de conflictos, pero que también asume, como en otros temas, una considerable dosis de realismo.

\section{Conclusiones}

El tratamiento discursivo sobre el tema migratorio, en el presente de México, revela la preponderancia de un enfoque proactivo por parte del gobierno de Andrés Manuel López Obrador, respecto a la crisis. Ante este reto, la actual Administración mexicana ha asumido la cooperación con otras naciones y organismos internacionales, la inversión social para el desarrollo en Centroamérica y México, y el tratamiento a los derechos humanos como oportunidades para el 204 desarrollo. La gestión dirigida por López Obrador busca trascender el enfoque defensivo que predomina en el contexto internacional contemporáneo.

Por otro lado, el análisis de las conferencias de prensa y posturas del gobierno muestra que una de las influencias más importantes de su política migratoria son los acuerdos alcanzados con Estados Unidos. Así, la influencia norteamericana catalizó el componente de control-contención en la estrategia

\footnotetext{
${ }^{46}$ "Impactos de la política migratoria de México en la frontera sur. Hallazgos de la misión de observación de la crisis humanitaria de personas migrantes y refugiadas en el sureste mexicano", San Cristóbal de las Casas, 21 de noviembre, 2019.
} 
migratoria mexicana. Sin embargo, el gobierno de López Obrador, con una perspectiva que combina el nacionalismo con el realismo político, logró establecer una postura intermedia.

Tal postura se distingue por intentar que se cumplan los compromisos políticos contraídos con el gobierno norteamericano y, a su vez, incluir la cooperación con los países emisores. Esto con el fin de paliar las causas de la migración, preservar los intereses de México y aportar a la experiencia internacional en el tratamiento al problema. En el escenario inmediato, su política exterior se consolida como marco de referencia para los procesos de negociación, regulación, control y seguimiento al tema migratorio, a nivel nacional e internacional.

En el discurso político de López Obrador, se hace explícita la distinción entre migración opcional-voluntaria y migración forzada. Ello se demuestra al considerar el hecho de que, en una situación conflictiva y crítica, la libertad (decisión racional o planificada) y la necesidad se transforman en fuerzas contrarias y externas entre sí. La crisis social y el modelo neoliberal objetualizan a las ciudadanías, convirtiéndolas en componentes de movimientos cada vez menos voluntarios, cada vez más desprovistos de libertad para escoger y para actuar ordenada y racionalmente. Así, una migración más legítima y provechosa sería aquella en la cual la libertad se desprenda del control racional y previsible de la necesidad.

En el discurso de López Obrador, la migración del grupo o individuo empujados por la pura necesidad no aparece totalmente deslegitimada, pero sí se recibe un fuerte cuestionamiento, por el carácter elemental de respuesta, inclinada a crear peligrosidad y espacios de conflicto para los grupos y países implicados. Superar este tipo de flujo migratorio y de migrante objeto es uno de los objetivos declarados del discurso. Su interpretación de los conceptos de libertad y derechos migratorios resulta contradictorio, en la medida que uno de los aspectos de su respuesta se apoya en el control y la contención.

La ilegalidad, el desorden y la desregulación no son considerados en este caso como componentes de la libertad migratoria, sino como factores que alimentan la migración forzada y, por ello, que resulta menos libre. Por otro lado, la inversión para el desarrollo en los países emisores se presenta como herramienta para disminuir y, a largo plazo, erradicar el peso de la pura necesidad de subsistencia en el impulso migratorio individual y colectivo.

La reaparición del migrante sujeto $u$ opcional sería un posible medidor de la efectividad de la política trazada ante la crisis. En ese orden, cobra significado el enfoque de inversión para el desarrollo aplicado no solo a los países centroamericanos, sino al propio México, como país de tránsito. Para 
el corto y mediano plazo, este enfoque del gobierno mexicano resulta promisorio y eficaz. Sin embargo, a largo plazo, las causas estructurales de la crisis migratoria no son solucionables solo con los elementos de control, legalidad y contención.

Si no se resuelve la crisis económica que potencia el aumento de la pura necesidad de subsistencia, quedarían latentes las fuentes de la migración en forma de avalancha descontrolada y crítica. La segunda dimensión de la propuesta mexicana (inversión para el desarrollo) se encamina a solucionar estos problemas estructurales. Sin embargo, la falta de desarrollo de esta segunda dimensión sería un factor desequilibrante, capaz de anular los resultados alcanzados.

Si hoy, a corto plazo, las vías por las cuales se movió ese flujo pueden ser controladas, sin la cooperación ni la gran inversión social, los futuros migrantes-objeto, forzados nuevamente por la crisis de sus fuentes de vida y las redes de tráfico de personas encontrarian nuevas vías para dar respuesta a la realidad estructural.

\section{Bibliografía}

Canales lizaola, Laura y lizÁrraga Salas, Frambel, "El efecto Trump: la migración mexicana en la agenda mediática de la prensa de México y Estados Unidos: La Jornada, El Universal y La Opinión”, Revista Interdisciplina, vol. 7, núm.18, p. 127-147. Disponible en: http://www.revistas.unam.mx/index.php/inter/article/ download/68977/61390

Castillo, Manuel Ángel, "Fronteras, migración y seguridad en México", Alteridades, vol. 15, núm.30, pp. 51-60. Disponible en: https://alteridades.izt.uam.mx/index. php/Alte/issue/view/21/showToc

Collet, Elizabeth y Le Coz, Camille After the Storm. Learning from the EU Response to the Migration Crisis, Bruselas, Migration Policy Institute Europe, 2018.

Cordero Díaz, Blanca laura y Garibo García, María Georgina, "Violencias encarnadas: migración de mujeres centroamericanas", en Nayar López Castellanos (coord.), Procesos migratorios en la Centroamérica del siglo XXI, México, UnAM, 2018, pp. 171-194.

Cuevas Romo Ana, Méndez Valencia, Sergio y Hernández-Sampieri, Roberto, Manual de introducción a Atlas.ti 7, México, Universidad de Celaya-Instituto Politécnico Nacional, 2014.

Dominguez Martín, Rafael, "Migración y desarrollo: mitos tóxicos e incoherencia de políticas en la Unión Europea”, en Ada Elsa Cabrera García, Gustavo Rodríguez Albor e Ibelis Blanco Rangel (coords.), Migraciones internacionales en el siglo XXI. 
Un análisis desde una perspectiva crítica, Puebla, Instituto de Ciencias Sociales y Humanidades “Alfonso Vélez Pliego" de la Benemérita Universidad Autónoma de Puebla, 2019. Disponible en: http://repositorio.uac.edu.co/handle/11619/3940 DuRAND, JoRge, "Política migratoria: entre el discurso, la práctica y la coyuntura" Foro Internacional, vol. 59, núm. 34, 2019. Disponible en: http://dx.doi.org/10.24201/ fi.v59i3-4.2650

"Impactos de la política migratoria de México en la frontera sur. Hallazgos de la misión de observación de la crisis humanitaria de personas migrantes y refugiadas en el sureste mexicano", San Cristóbal de las Casas, 21 de noviembre, 2019.

Rodríguez ArRieta, José Daniel, "Discursos políticos sobre la inmigración presentes en los programas de gobierno del proceso electoral de Costa Rica 2017-2018", Revista Rupturas, vol. 9, núm. 2, pp. 39-61. Disponible en: https://doi.org/10.22458/ rr.v9i2.2522

Rodríguez Rodríguez, Rogelio, "Desafíos de México frente al fenómeno migratorio en la segunda década del siglo XXI, un reto como política pública”, Revista Interdiciplinaria de Estudios Latinoamericanos, vol. 3, núm. 3, p. 81-100. Disponible en: http://cresur.edu.mx/OJS/index.php/RIEL_CRESUR/article/view/487

ToRre-CANTALAPIEDRA, EduARDo, "Violencia, migración y refugio: una mirada reflexiva a contribuciones sobre violencia estructural y movilidad geográfica", Huellas de la Migración, vol. 4, núm. 7, pp. 139-171. Disponible en: https://huellasdelamigracion.uaemex.mx/article/view/11980

Villafuerte Solís, Daniel y María del Carmen García Aguilar, "Crisis del sistema migratorio y seguridad en las fronteras norte y sur del México", Revista Interdisciplinar da Mobilidade Humana, año 23, núm.44. Disponible en: http://www.scielo.br/pdf/ remhu/v23n44/1980-8585-REMHU-23-44-083.pdf

Zapata-Barrero, Ricard, Fundamentos de los discursos politicos en torno a la inmigración, Madrid, Trotta, 2009. 